\title{
Desplazamientos, silencios y materialidad. La comunidad de Basilio Curruhuinca en el sudoeste de Chubut, Patagonia Argentina
}

\author{
Displacements, Silences and Materiality. The community of Basilio
}

Curruhuinca in the southwest of Chubut, Patagonia Argentina

\author{
María Laura Casanueva \\ Instituto Nacional de Antropología y Pensamiento Latinoamericano (INAPL), Argentina
}

RESUMEN Desde una mirada microhistórica, el enfoque arqueológico, histórico y antropológico puesto en práctica, busca traer a la memoria el asentamiento de la comunidad del cacique Basilio Curruhuinca y sus vivencias cotidianas, luego del traslado forzado hacia Chubut como consecuencia de las campañas militares de finales del siglo XIX. Esta comunidad, desprendimiento de la de Bartolomé Curruhuinca de la zona del lago Lacar, logró asentarse teniendo viviendas, siembras y ganados; sin embargo, el destino de estas familias fue el corrimiento paulatino hacia áreas marginales. A poco más de 100 años de su establecimiento en el sudoeste de Chubut, el recuerdo endeble de su presencia se contrapone a los vestigios materiales que quedaron de su asentamiento, junto a fragmentos de la memoria local. La investigación arqueológica aquí presentada intenta recuperar la forma de vida y la cotidianeidad de los hoy casi desconocidos y olvidados habitantes mapuches de Alto Río Mayo, a escasos kilómetros de Aldea Beleiro.

PALABRAS CLAVE Sudoeste de Chubut; comunidad Curruhuinca; asentamientos indígenas recientes; arqueología Histórica. 
ABSTRACT From a microhistorical point of view, the archaeological, historical and anthropological approach put into practice seeks to recall the settlement of the cacique Basilio Curruhuinca community and their daily experiences, after the forced transfer to Chubut, as a consequence of the military campaigns at the end of the XIX century. This community, detached from that of Bartolomé Curruhuinca in the Lacar Lake area, managed to settle, have homes, crops and livestock; however, the fate of these families was the gradual movement towards marginal areas. A little over 100 years after its establishment in the southwest of Chubut, the weak memory of its presence is contrasted with the material remains of its settlement, along with fragments of local memory. The archaeological research presented here attempts to recover the way of life and everyday life of the now almost unknown and forgotten Mapuche inhabitants of Alto Río Mayo, a few kilometers away from Aldea Beleiro.

KEYWORDS Southwest of Chubut; Curruhuinca community; recent indigenous settlements; Historical Archeology.

\section{Introducción}

El área de Aldea Beleiro, paraje rural ubicado al sudoeste de la provincia de Chubut y a escasos $5 \mathrm{~km}$ del límite internacional con Chile, se caracteriza por su belleza y su ocupación prolongada en el tiempo. Desde hace 9000 años aproximadamente (Castro Esnal et al., 2017) comunidades de cazadores recolectores habitaron la zona y ocuparon el sitio Casa de Piedra de Roselló, un espacio conformado por una cueva principal y dos aleros ubicados en las márgenes del arroyo Nirihuao (Dal Molin, 1998), en donde las investigaciones arqueológicas han demostrado hasta el momento su ocupación desde el Holoceno temprano hasta entrado el siglo $\mathrm{XX}^{1}$ (Castro Esnal y Casanueva, 2018).

La investigación arqueológica de tiempos históricos recientes en la zona, iniciada en el año $2011^{2}$, se concentró en las capas superiores de este sitio y en las ocupaciones vecinas de colonos criollo-europeos, representadas por actuales taperas que representan los restos de las primeras viviendas levantadas de forma permanente desde principios del siglo XX (Casanueva, 2016).

\footnotetext{
1. Esta investigación forma parte del Proyecto "Arqueología del poblamiento y contacto europeo-indígena en la provincia de Chubut. Estrategias de aprovechamiento ambiental y relaciones sociales. Dirigido por la Dra. Cecilia Pérez de Micou y codirigido por las Dras. Analía Castro Esnal y María Laura Casanueva (Instituto Nacional de Antropología y Pensamiento Latinoamericano -INAPL- y Secretaría de Cultura de Chubut. Esta investigación ha sido financiada por la UBA, el CONICET y la ANPCyT (Proyectos UBACYT F219, PIP 084, PIP 023, PICT 2015-2141).

2. Subproyecto dentro del anterior: "Arqueología Histórica en la Provincia de Chubut. Vida cotidiana en la frontera interétnica" Responsable M. L. Casanueva.
} 
Estas investigaciones fueron profundizándose con los años y el correlato arqueológico de las primeras ocupaciones de inmigrantes principalmente españoles, fue acompañándose por entrevistas a pobladores locales, lectura bibliográfica y estudio de distintos documentos históricos.

Estos acercamientos fueron abriendo una nueva línea de investigación que completaba la ocupación histórica del área, la oficialmente reconocida. Fue así que familiarizados con apellidos españoles, chilenos y tehuelches (estos últimos vecinos de la cercana colonia indígena del Chalía) comenzamos a oír hablar de Curruhuinca (Castro Esnal y Casanueva, 2018), este apellido mapuche comenzó a relacionarse con algunos del Chalía y otros presentes en las cartas topográficas locales. De esta manera se dio inicio al estudio de la historia del cacique Basilio Curruhuinca y su comunidad (Asentados en Alto Río Mayo a escasos kilómetros de Aldea Beleiro) (Figura 1), su traslado hacia el sur luego de la campaña del desierto, la repartición de tierras, el despojo paulatino de las mismas y las vivencias cotidianas de una de las familias del grupo de este cacique.

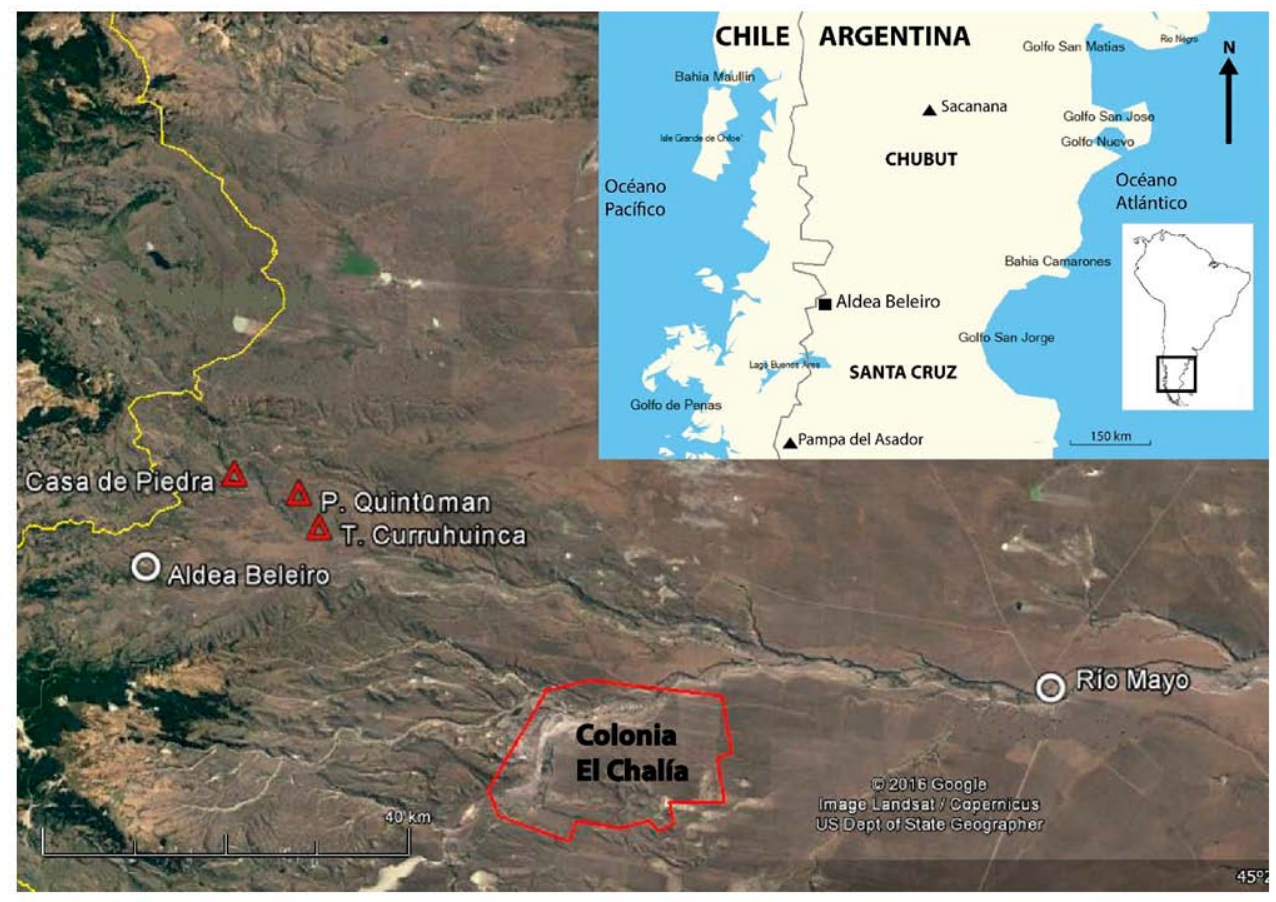

Figura 1. Ubicación del área de investigación e identificación de los sitios arqueológicos mencionados en este trabajo (Mapa realizado por Analía Castro Esnal). 
Este trabajo presenta los resultados alcanzados hasta el momento sobre el estudio del emplazamiento de Basilio Curruhuinca, y como parte de su grupo, el devenir de la familia Miranda-Quintoman, cuyos vestigios materiales nos condujeron a uno de los descendientes, los restos de la vivienda primigenia, su vida cotidiana, costumbres y el devenir familiar.

La presencia mapuche en la zona, notoriamente "olvidada", queda de manifiesto hoy en escasas menciones toponímicas, en la endeble memoria local y en pobres restos materiales de las vivencias ocurridas en la zona durante la primera mitad del siglo XX.

Este artículo despliega el estudio histórico-antropológico efectuado en el área, pero principalmente el abordaje arqueológico de los restos materiales relacionados con el asentamiento de Basilio Curruhuinca. Si bien estamos en proceso de búsqueda histórica y en plena investigación, es nuestra intención volver a traer a la memoria a los miembros de aquel grupo mapuche, visibilizando sus esfuerzos, su presencia y su humanidad. Para esto proponemos, desde un enfoque microhistórico, un estudio multidisciplinario que contempla los abordajes teórico-metodológicos de la Arqueología, la Historia y la Antropología (Casanueva, 2013).

\section{Marco teórico- metodológico de la investigación}

La arqueología como disciplina humanística, asimilada a la teoría social, permite el abordaje teórico y abstracto del actor humano, de su conciencia y su acción, de las condiciones y consecuencias estructurales que de él proceden (Acuto y Zarankin, 1999). En esta línea, se sostiene que es "gente concreta" la que hace la historia y, por lo tanto, a través del enfoque teórico y metodológico aquí propuesto, se busca hacer una historia de personas (Lumbreras, 2005). Desde esta postura se consideran ciertos principios planteados por la microhistoria, práctica historiográfica íntimamente ligada con la antropología (Levi, 1993), la apuesta de la experiencia micro-social "es que la experiencia más elemental, aquella del grupo pequeño, incluso el individuo, es la más esclarecedora porque es la más compleja y porque se inscribe en el mayor número de contextos diferentes" (Revel, 1995, p. 138).

La postura microhistórica se basa, en esencia, en la reducción de la escala de observación, en un análisis microscópico y en un estudio intensivo del material documental. Giovani Levi (1993) plantea, en primer lugar, que cada actor histórico participa, de cerca o de lejos, en procesos de dimensiones y niveles diferentes, del más local al más global. No existe entonces un corte, ni oposición, entre historia local e historia global (Ginzburg, 1994). En definitiva, este enfoque busca hacer aparecer regularidades en los comportamientos colectivos de un grupo social particular sin perder lo que cada individuo, familia o grupo tiene de particular. La práctica microhistórica, por lo tanto, orienta nuestra investigación, siendo uno de los objetivos de nuestro trabajo re- 
cuperar la microhistoria del área (Levi, 1993; Revel, 1995) poniendo el eje, desde una mirada local y regional, en la convivencia de los distintos grupos sociales, su vida cotidiana y los espacios domésticos y productivos en los que se desarrolló su vida diaria.

Se tiene plena consciencia que ni texto, ni objeto, ni oralidad, constituyen un reflejo directo de la sociedad que les dio origen, se sabe que estos recursos fueron (y son) manipulados en un contexto de relaciones sociales asimétricas (Quiroga, 2005), y sobre ellos, a su vez, actuaron distintos procesos de formación que incidieron en el registro que llegó hasta nosotros. Por lo tanto, la investigación aquí propuesta, busca dar sentido al mundo material del pasado a través de líneas de análisis independientes.

Se propone así, dentro de los estudios contemporáneos, una mirada multidisciplinaria (Ramos, 2002), en la que se integran las herramientas teórico-metodológicas de la Arqueología (prospecciones, levantamiento de plantas de viviendas, estudio de materiales muebles, sondeos, excavaciones, etc.), de la Historia (estudios de catastros, censos, registros civiles y judiciales, fotografías, mapas, etc.) y de la Antropología (a través de entrevistas a pobladores locales y descendientes de pioneros e indígenas apostados desde el siglo XIX y XX) (Casanueva, 2010; Casanueva et al., 2019; Castro Esnal y Casanueva, 2018; García et al., 2009). Esta visión permite abordar las distintas problemáticas de forma completa, contrastando tanto el aporte de la cultura material (mueble e inmueble), como el de las fuentes gráficas y escritas (primarias y secundarias) y las historias de vida y relatos orales. El resultado de este abordaje es un acercamiento integrador de los primeros momentos de ocupación y contacto entre indígenas y europeo-criollos en el área bajo estudio.

Desde esta postura, la dilucidación de los problemas planteados en esta investigación no puede prescindir tanto de los registros escritos y/o gráficos, como de los testimonios orales, los que juegan un rol importante ya que contribuyen a la construcción del tema de investigación mismo. Por otro lado, permiten formular el contexto dentro del cual interpretar el registro arqueológico y a partir del cual derivar algunas de las preguntas arqueológicas. Así también, su colaboración no se reduce al establecimiento de los "hechos", sino que permite formular hipótesis explicativas de determinados niveles de fenómenos (Casanueva, 2005).

Dentro de este marco y para dar respuesta a los interrogantes planteados, se consideran dos aproximaciones analíticas, una macro y otra micro. Una aproximación macroanalítica es la que abarca el ámbito de la historia mundial, nacional y provincial. En cambio, una aproximación microanalítica implica un análisis a escala reducida contemplando, por un lado, una aproximación microhistórica (como la ya descripta) al paisaje local, en el sentido de "historia local", y por otro, una aproximación antropológica-histórica a los aspectos socioculturales locales (Brittez, 1998/2004). 
El enfoque propuesto en esta investigación, como se dijo, permitió emplear herramientas teórico-metodológicas propias de la Antropología Social y de la Historia, haciendo uso tanto de las fuentes bibliográficas y secundarias referentes a la materia, como de las fuentes primarias (documentales y orales). Se considera que son estas últimas las que tal vez pueden brindar información más precisa y detallada de casos particulares.

Se sostiene que la explicación arqueológica objetiva puede aprovechar mucho, sin ningún daño de rigor analítico, de las tradiciones y relatos orales como fuente primaria de evidencia e interpretación de las formaciones sociales pasadas (Whiteley, 2002). Para esta investigación se optó por el método de recolección de datos por entrevistas considerándolo el método más directo para acceder a detalles de vida, sentimientos y juicios. El universo de la entrevista es amplio, sin embargo, este abordaje se circunscribió a las entrevistas abiertas y/o semiestructuradas, que si bien con un guion establecido previamente no se atan a un orden de preguntas rigurosas, son oportunas también en función de la relación y grado de confianza con las personas entrevistadas, a su vez alientan el fluir discursivo del entrevistado a lo largo del encuentro (Montañés Serrano, 2001).

Se efectuaron, por lo tanto, entrevistas abiertas a los miembros de dos de las familias descendientes de los primeros pobladores europeos y a su vez dueños de los campos donde se encuentran algunos de los sitios arqueológicos estudiados, así mismo, se entrevistó a un descendiente de los pobladores del Puesto Miranda-Quintoman. No se especifican los nombres de los entrevistados porque se realizó con ellos un acuerdo de confidencialidad, por lo tanto, a lo largo de todo el artículo, se identifica a los entrevistados con sus iniciales. Estas entrevistas fueron realizadas por todas las investigadoras miembro del equipo de trabajo en el marco del Proyecto "Arqueología del poblamiento y contacto europeo-indígena en la provincia de Chubut Estrategias de aprovechamiento ambiental y relaciones sociales" dirigido por la Dra. Cecilia Pérez de Micou (INAPL y Secretaría de Cultura de Chubut); ocurrieron en Aldea Beleiro y Alto Río Mayo (Chubut) durante los trabajos de campo de noviembre 2013, enero 2016 y enero/febrero 2019. También se efectuaron entrevistas virtuales vía WhatsApp y Zoom (mayo y junio 2020) a descendientes del linaje Curruhuinca y de la familia Quintoman.

En cuanto a la relación entre la arqueología y la fuente documental, se sostiene que son diferentes e independientes, cada línea de evidencia posee su propia historia, escala y resolución, pero se las entiende como resultado de los mismos procesos sociales y por lo tanto factibles de ser integradas en el mismo proceso de análisis e interpretación (Buscaglia y Bianchi Villelli, 2009). Para este análisis se contemplaron no sólo las fuentes sino también los contextos y condiciones de producción de las mismas, ya que se cree que los procesos de formación de las fuentes son tan impor- 
tantes como los del registro arqueológico. Se adhiere a la idea que manifiesta que cada visión del pasado es producto de su propio tiempo, en consecuencia los registros históricos hacen declaraciones, ofrecen opiniones, toman partido y responden a intereses subyacentes (Bellelli, 1999; Nacuzzi y Lucaioli, 2011). La producción de fuentes documentales para Patagonia durante el siglo XIX no puede ser disociada de la conformación del Estado nación argentino, su desarrollo y sus intereses, aún más en zonas fronterizas como la estudiada donde, a finales de este siglo, primaba la necesidad de establecer límites claros entre Chile y Argentina que permitieran ejercer las soberanías nacionales. El principal documento histórico estudiado aquí (Censo de las familias Indígenas de $1927^{3}$ ) fue confeccionado por un inspector del Ministerio de Agricultura de la Nación y presentado en 1927 al gobernador de los Territorios del Chubut; este documento además de brindar valiosa información de los asentamientos indígenas en la zona, representa el ideal de territorialización nacional de finales del siglo XIX y principios del XX y se encuentra dentro del marco de la Ley de Tierras de 1903 (Memoria del Ministerio de Agricultura 1902-1903, p. 185, citada por Delrío, 2005), generada en concordancia con la idea de poblar las tierras extraídas a los indígenas luego de la Campaña del Desierto.

\section{Contexto Histórico}

Los orígenes de Aldea Beleiro se remontan a las últimas décadas del siglo XIX cuando se posicionó como sector de cruce de caminos hacia ambos lados de la cordillera, producto de la consolidación del intercambio comercial entre Chile y Argentina [Maggiori, 2007 y entrevistas a pobladores locales (P. y P.PB., Aldea Beleiro, enero 2016)]. Entre 1910 y 1916 comenzaron a llegar los primeros inmigrantes españoles con intenciones de trabajar cerca de la frontera y lograr tierras en propiedad para establecerse. Cabe mencionar que el interior de la Patagonia fue poblado por inmigrantes muy tardíamente, hasta bien avanzado el siglo XIX continuaba siendo habitada por grupos indígenas, con circuitos de movilidad amplios necesarios para abastecerse de los distintos recursos para su subsistencia y para realizar contactos con otros grupos, tanto de indígenas como de colonos (Castro, 2014). Es en ese momento que comienza la inmigración organizada por el Estado argentino con contingentes europeos (Ej. Galeses/Boers) y otra de hombres solos o familias aisladas sin apoyo estatal, como es el caso de esta región que aquí se presenta (Casanueva, 2013).

3. Censo de las Familias Indígenas de 1927. Inspección compuesta por las tribus de los caciques Manuel Quilchamal y Basilio Curruhuinca y sus haciendas. Instituto Autárquico de Colonización y Fomento Rural de Chubut (IAC), Rawson, Gobernación del Chubut (En adelante CFI 1927, Expte. 345-2961). 
Se sabe que lo que hoy es Aldea Beleiro, en sus inicios formaba parte de Alto Río Mayo, llamándose Aldea Escolar, Aldea Beleiro es nombrada así recién en 1974. La creación de la institución escolar (Escuela $\mathrm{N}^{\circ} 71$ ) dio origen al pueblo, ya que se toma como fecha de fundación el 22 de septiembre de 1922, año en que se inauguró la misma, cuyo objetivo principal era alfabetizar a los niños indígenas de la zona (Barrionuevo y Beleiro, 2015). Se reconoce que era primordial para el Estado nacional, a principios del siglo XX, afianzar su presencia en la frontera y "argentinizar" a los indígenas diferenciándolos de la población chilena; se infiere, por lo tanto, que para el año 1922 habría bastantes niños indígenas para tener la necesidad de alfabetizarlos y establecer una escuela fronteriza. La escuela de la vecina colonia del Chalía data de unos cuantos años después, no se tienen datos precisos pero se sabe que para la década de 1950 ya funcionaba (García, 2009).

En definitiva, la historia reciente de Aldea Beleiro, fue definida decisivamente por los europeo-criollos en un contexto en el que los indígenas fueron quedando al servicio como puesteros, peones o jornaleros de los nuevos terratenientes ganaderos (Casanueva, 2013; Casanueva, 2016; Cirigliano, 2016; Nuevo Delaunay et al., 2014). La presencia indígena era importante durante estos momentos históricos, desde los ya ancestralmente establecidos tehuelches -consecuencia de su presencia fue la creación de la Colonia Indígena de El Chalía en 1916--, como los mapuches que provenían del norte (de la zona del Lago Lacar). Estos últimos fueron trasladados forzosamente hacia el sur luego de la Campaña del Desierto ocurrida entre 1879-1883 (Delrío, 2010; Dumrauf, 1981; Habegger, 2007; Pérez, 2015; Pinotti 2001, entre otros), e instalados por el Estado argentino en esta área en 1912 aproximadamente. Atestigua esta presencia el mencionado censo de población indígena realizado en 1927, documento en el cual se contabilizan las familias y sus posesiones (vivienda, plantaciones, ganado, etc.) tanto tehuelches como mapuches, las que respondían a los caciques Manuel Quilchamal y Basilio Curruhuinca, respectivamente (CFI 1927, Expte. 345-2961). Durante el modelo agroexportador (1869-1930), precisamente en los censos e inspecciones de tierras, la agricultura y la ganadería ocupaban un lugar muy importante en las estadísticas (luego de la temática poblacional y la educación), en concordancia con las bases productivas del modelo (Novick, 2002).

4. La colonia Indígena de El Chalía fue creada el 28 de febrero de 1916 para el cacique Manuel Quilchamal y su gente, en los campos linderos al arroyo Chalía, con una extensión originaria de 6o.oooha (Muñiz y Perea, 200o). 


\section{El linaje Curruhuinca y los datos surgidos de los documentos primarios}

La comunidad Curruhuinca, de profunda raigambre en la zona de San Martín de los Andes (Habegger, 2007; Pérez, 2015; Valverde y Stecher, 2006) tuvo en Neuquén como estrategia las negociaciones políticas durante las avanzadas del Estado Nacional sobre los territorios indígenas. Incluida entre los grupos que respondían a Sayhueque, esta comunidad tenía su territorio en las cercanías del lago Lácar (Habegger, 2007; Pérez, 2015). El cacique Bartolomé Curruhuinca participó de la fundación de San Martín de los Andes, su allegada política hizo que fuera uno de los firmantes en el acto de fundación, el 4 de febrero de 1898 (Dumrauf, 1981; Habegger, 2007; Pérez, 2015).

En cuanto a la posible relación entre Bartolomé y Basilio, luego de la lectura de completas y complejas investigaciones sobre la Comunidad Curruhuinca, principalmente la efectuada por Pérez (2015), sumado al intercambio personal con el autor, a lo que se adiciona el contacto directo con un tataranieto del cacique Bartolomé $\mathrm{Cu}$ rruhuinca (A.C., Tierra del Fuego vía WhatsApp, mayo 2020), con el que intentamos deducir y completar su árbol genealógico; interpretamos que Basilio Curruhuinca -nacido en 1839 según cálculos efectuados a partir de la información del Censo de 1927 (CFI 1927, Expte. 345-2961)-, podría haber sido un hermano mayor de Bartolomé (nacido en 1845 aproximadamente).

Hermano o pariente de Bartolomé, Basilio habría liderado un desprendimiento del grupo mayor, luego de la reubicación de Bartolomé y su gente en Quila Quina, como consecuencia de la fundación de San Martín de los Andes (Pérez, 2015). El grupo liderado por Basilio Curruhuinca fue forzosamente trasladado hacia la provincia de Chubut, siendo su lugar de residencia desde 1912 la zona de Alto Río Mayo; en esta zona su forma de asentamiento y la economía familiar remiten a las costumbres propias de la comunidad Curruhuinca en Neuquén, y demás comunidades mapuches, como la estructura social agro pastoril de pequeños productores minifundistas y de asentamientos sedentarios (Pérez, 2015; Pinotti, 2001; Valverde y Stecher, 2006, entre otros). Para 1927, en Alto Río Mayo, las familias censadas se encontraban asentadas en viviendas de adobe y zinc, poseían galpones y corrales, haciendas y chacras, huertas y sembradíos y marcas de ganado propias.

\section{Un documento casi desconocido}

Retomando el Censo Indígena de 1927 (CFI 1927, Expte. 345-2961), este se llevó a cabo por un inspector del Ministerio de Agricultura de la Nación. Se sabe que para las autoridades nacionales los indígenas eran sólo visibles como "gente" de algún cacique (Delrío, 2005), por lo tanto el documento en cuestión tiene como referencia a Basilio Curruhuinca. En este documento, tan representativo de la territorialización nacional de finales del siglo XIX y principios del XX, se utiliza el concepto de tribu, 
englobándose bajo él a diversas familias e individuos, no todos mapuches; aquí también se distingue el discurso hegemónico que implicó una visión homogeneizante de la sociedad indígena (Delrío, 2005).

Luego de las campañas militares de fines del siglo XIX, la mayor parte de los decretos y de las leyes de asignación de tierras a indígenas operaron bajo la idea de tratar con "agrupaciones", "restos de tribus" o simplemente "gente que quedaba" de determinados "caciques". En algunos casos sólo se hacía referencia a la familia más cercana de determinado "cacique" y la conformación de cada una de las nuevas comunidades fue generalmente resultado de la agregación de nuevas familias e individuos (Delrío, 2005, p. 113). Esta concepción se ve plasmada en la descripción manifiesta en el documento citado, donde estos conceptos quedan claramente en evidencia, el de tribu, el cacique interlocutor con el Estado y la agregación de familias a las que se les dio una identificación muy vaga.

Nuestro equipo de investigación ha realizado un profuso trabajo antropológico y arqueológico en la Reserva Indígena del Chalía, ubicada al este de Aldea Beleiro a una distancia aproximada de $45 \mathrm{~km}$ (Castro Esnal et al., 2011; Castro Esnal, 2014; Castro Esnal et al., 2020; Pérez de Micou et al., 2009; Sacchi, 2012). Los datos allí obtenidos y analizados complementan los surgidos en el área de trabajo y vecina de la reserva mencionada. Según los testimonios obtenidos de entrevistas realizadas a descendientes del cacique acuerdan en afirmar que "los Curruhuinca y su gente provenían de la zona de San Martín de los Andes" [Entrevistas realizadas en el Chalía y Río Mayo: descendientes de Mercedes Curruhuinca (hija de Basilio Curruhuinca y Josefa Copolki) -Silvia García, com. pers.-], dato que concuerda con las investigaciones históricas sobre esta comunidad.

El asentamiento de Basilio Curruhuinca en Alto Río Mayo está registrado desde el año 1912 según el documento histórico de referencia (Figura 2). Muy probablemente desde el momento del traslado, que podría haber ocurrido entre 1883 (fin de las campañas militares en el área andina) y 1898 (Fundación de San Martín de los Andes) (Dumrauf, 1981; Habegger, 2007; Pérez, 2015; entre otros) este grupo, o parte de él, podría haber tenido un paso previo por Sierra Nevada ${ }^{5}$ [(Perea, 1998 y testimonio de J.S. (Aldea Beleiro, febrero 2019)]. Es de destacar que Alto Río Mayo se ubica a escasos km de lo que hoy es Aldea Beleiro, y aledaño a la Colonia del Chalía del cacique Manuel Quilchamal. Los grupos de ambos caciques estrecharon una profunda relación, muchas uniones y descendencia entre ellos han quedado de manifiesto en los documentos, en las entrevistas realizadas, en las investigaciones en la zona y en la

5. Sierra Nevada es una alineación montañosa perteneciente a los departamentos Paso de Indios, Sarmiento y Río Senguer, se encuentra hacia el este y al norte de nuestra área, y al norte del lago Musters. 
consecuente bibliografía producida (Aguado, 2007; Musso, 2015; Pinotti 2001, 2004; etc.).

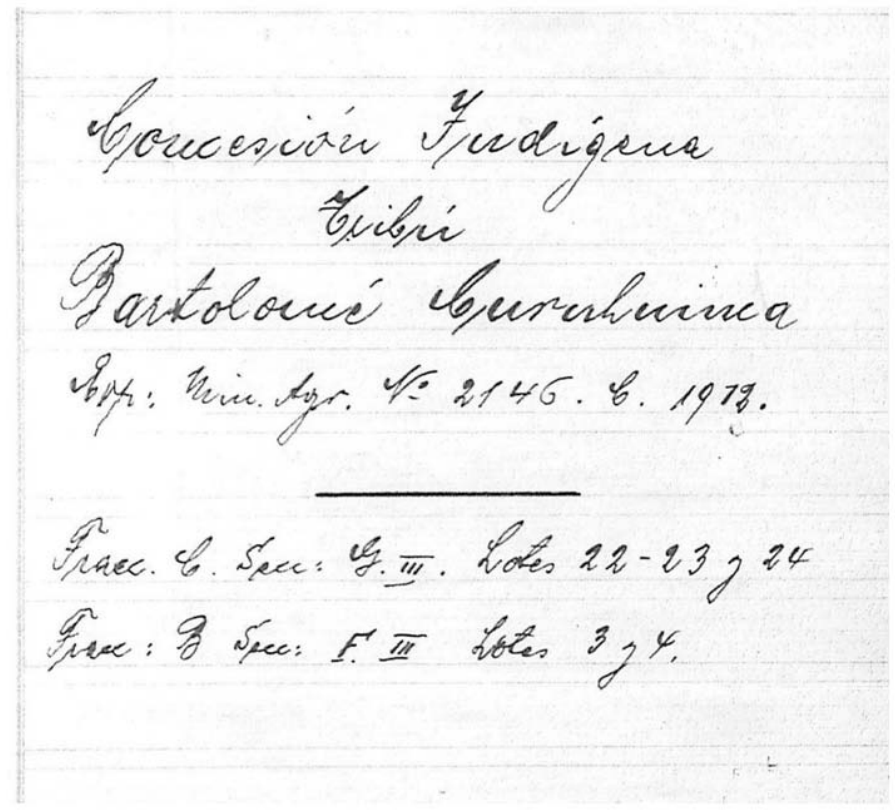

Figura 2: Carátula donde se especifica: "Concesión Indígena Tribu Bartolomé $\mathrm{Cu}-$ rruhuinca" Año 1912, y bajo la cual se ubica en Alto Río Mayo al Cacique Basilio Curruhuinca y su grupo (“Censo de las Familias Indigenas de 1927” Expte. 345-2961).

La propiedad de la tierra y los bienes

Como se ha dicho, es probable que parte del grupo de Basilio Curruhuinca haya tenido un lugar de asentamiento previo (o inclusive posterior) al de Alto río Mayo en Sierra Nevada, en donde hasta aún en la actualidad quedan varios apellidos de las familias que conformaban su grupo (Quintomán, por ejemplo). En esta línea, Perea (1998) ha investigado los reclamos de tierras por parte de los indígenas del sur del Chubut y para 1930 en adelante relata infinidad de estafas, engaños, hurtos y apropiación de tierras y como damnificados menciona (con documentación probatoria y relatos orales) algunos de los apellidos mencionados en el censo de 1927 (Llanca, Quintoman, Catriquil (o Catriquir) - CFI 1927, Expte. 345-2961) (Figura 3). 


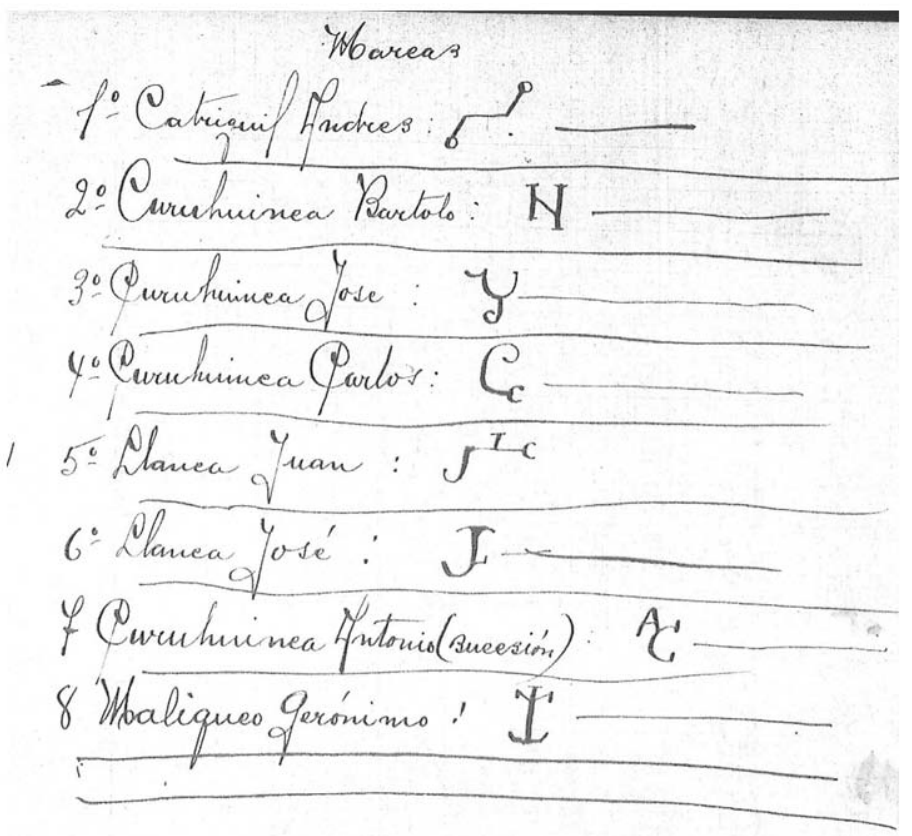

Figura 3: Marcas de ganado registradas en el documento de 1927, donde pueden leerse los apellidos mencionados (“Censo de las Familias Indígenas de 1927” Expte. 3452961).

Casualmente, estos sucesos ocurrieron luego de que en 1927 se registraran todos los bienes, propiedades y mejoras en los lotes ocupados por los indígenas censados. No es desconocido el accionar de los distintos funcionarios e inspectores de tierras, alineados y funcionales al Estado Nacional (Baeza, 2007; entre otros); muy probablemente la información recogida y elevada a las autoridades nacionales sirvió de "trampa" para las familias indígenas, cayendo casi inmediatamente sobre ellas distintos atropellos y violaciones que resultaron en sus desalojos paulatinos.

Muchos de estos sucesos, denunciados por Irineo León como miembro de la Liga Patriótica Argentina, ocurrieron en Sierra Nevada, Loma Redonda, El Chalía y Alto Río Mayo (Perea, 1998, p. 65), de este último lugar se presenta el testimonio de Juan Llanca (Lote 4, CFI 1927, Expte. 345-2961):

“...El Señor Juan Llanca, se presenta ante mí y expone:

Que siendo el día 28 de diciembre en circunstancias en que llanca y su puestero se encontraban ausentes se, presentó en su Domicilio de alto Río Mayo el Sr. Marcos Alberdi y su socio Baltasar Mera y como si fuesen autoridad ó dueños de mis frutos é intereses procedieron a contar los lienzos de lana y según manifiesta su Señora le dijeron que tenían también que contar la hasienda hecho que Llanca dio cuenta al Comisario local quien dice Llanca, que le manifestó el comisario que lo atasen y diesen cuenta a la policía: si 
volvía a repetirse el caso...” (Defensa de Irineo León frente al Presidente de la Comisión C. de Organización, Coronel Don Juan M. Picabea. Alto Río Senguer. Enero 11 de 1930, testimonio citado en Perea, 1998, p. 67).

Juan Llanca perteneciente a la comunidad de Basilio Curruhuinca, tenía cuenta y deudas con la Casa Lahusen y Cía Ltda. en Río Mayo, esta casualmente tuvo una participación fundamental en el derrumbe y desaparición de los indígenas del área:

“...hasta ahora nuestra situación sigue en el agravante de un pronto derrumbamiento final, los arreos ${ }^{6}$ que se están por sacar por cuenta de la casa Lahusen y Cía Ltda. Sea el mayor derrumbamiento de estos lugares: ;Qué hara el poblador sin hasienda $;$ Que harán las flias, privadas ya del único alimento y sostén que es la carne! Con qué elemento podrá contar el poblador! ... en vano pedimos socorro por la desnudes y el hambre en vano prevengo que los niños están descalsos y desnudos en vano clamo que las mercaderías se están pagando a presios exsorbitantes y que nuestros frutos no tienen ninguna acectación..." (Reclamo de Irineo León al Gobernador del Territorio de Chubut, enero 6 de 1931, Alto Río Senguer, cito en Perea, 1998, p. 97).

En relación a los abusos y desalojos de los indígenas Eugenio Tello, el segundo Gobernador del Chubut, decía en un estudio sobre "EI Chubut y sus primeros pobladores":

"Según estos, los especuladores en certificados se tomarán la mejor tierra del Chubut... Y en verdad que no deja de ser desconsolador, por no decir irritante, el contemplar a centenares de labriegos argentinos, hijos de beneméritos patriotas, sumidos en la miseria, sin un palmo de tierra propia para albergar a su familia y dignificarse; mientras que parece preocuparnos, únicamente la suerte de los inmigrantes, en cuyo beneficio casi exclusivamente se dictan las leyes protectoras, pero no por eso debemos olvidar al criollo, que estimulado trabaja como un inmigrante, y que en justicia debe tener los beneficios, así como ellos y sus padres tuvieron una buena parte en las lides de la Patria" (Tello, 1935, citado en Dumrauf, 1981, p. 25).

Los indígenas derrotados y desposeídos de sus tierras, explica Dumrauf (1981), rondaban de un lado para otro a medida que los lugares donde se les había permitido establecerse eran adquiridos por los latifundistas. La historia de las tierras destinadas a los indígenas se fue prolongando durante años y esta situación no fue distinta en nuestra área de estudio; esta modalidad se dio en todo el territorio y fue la manera

6. Se refiere a los animales que la Casa Lahusen solía tener en contratos prendarios con los pobladores locales (Perea, 1998, p. 97). 
de ir "haciéndose" de las tierras, arrinconando a los originarios y criollos en los márgenes menos fértiles y subsumidos en la miseria como consecuencia de una política de Estado adversa a ellos y beneficiosa y generosa con inmigrantes, empresarios y latifundistas (Baeza, 2007; Dumrauf, 1981; Perea, 1998).

El período de los largos peregrinajes fue un período caracterizado por dos instancias centrales en la negociación entre autoridades estatales y pueblos originarios: la concentración, las deportaciones y los traslados masivos de los indígenas y, posteriormente, el reclamo por la tierra; resultando evidente el proceso de marginación del indígena como el de acumulación de la tierra en manos del gran capital (Delrío, 2005, p. 91; Delrío, 2010; Perea, 1998).

Se sabe que el Estado consideraba que en las tierras del sur era la ganadería la forma de explotar los terrenos fiscales, ya que exigía baja densidad de población, se instalaba entonces como plan central de colonización de los territorios del Sur la idea de formar grandes reservas de tierras fiscales para articular la creación de nuevas colonias ganaderas, radicando allí a los contingentes dispersos de población originaria. El objetivo de este plan era, en definitiva, el fin de la tribu como entidad social y política. La localización de los indígenas en lotes individuales operaba hacia una individualización de la propiedad y la consiguiente disolución de la misma política tribal (Delrío, 2005, p. 144). Se reconocía, así, a estos grupos indígenas como "argentinos" y como "pobladores rurales pobres", invisibilizándolos y, dándose por terminado por lo tanto, el problema del indio (Delrío, 2005, p. 147).

El otorgamiento de tierra fiscal bajo este marco jurídico era factible en casos en los cuales se suponía cierto grado de "civilización alcanzada" por parte de los indígenas (esta comunidad mapuche agropastoril, evidentemente cumplía con estas expectativas) y, principalmente, donde las condiciones del terreno no las hiciesen apetecibles para el mercado (Delrío, 2005). Por lo tanto, la situación que se produjo con los indígenas fue de arrinconamiento en áreas marginales, como consecuencia de la disminución notoria de su territorio, las leyes impuestas por el capitalismo y el sistema productivo de estancias. Muchos de ellos pasaron a formar parte de éstas, logrando trabajos asalariados como puesteros, peones o jornaleros, inclusive caciques que, ante la finalización de las campañas militares, volvían a sus tierras y se ocupaban en los establecimientos rurales (Agnolin y Nuevo, 2016; Casanueva et al., 2019; Castro Esnal y Casanueva, 2018; Delrío, 2005; Dumrauf, 1981; Goñi, 2013; Habegger, 2007; etc.).

Es nuestra área un claro ejemplo de lo anteriormente dicho. La suerte que corrieron los indígenas fue muy poco próspera, fueron desplazados a áreas marginales con escasos recursos, paralelamente perdiendo sus tierras en gran parte a través de desalojos, robos, engaños, todos actos efectuados con el consentimiento y, muy probablemente, con el auspicio del Estado argentino, ya que tanto la policía fronteriza de Chubut, distintos jueces de paz, bolicheros, mercachifles, comerciantes, algunos 
colonos y ciertas compañías inescrupulosas, fueron arrebatándoles tierras y ganado, como el testimonio anteriormente mencionado lo explicita (Perea, 1998, p. 97). Infértiles fueron todos los reclamos efectuados por los mismos damnificados y a través de la Liga Patriótica Argentina, dirigida por Irineo León (Perea, 1998).

Consecuencia del accionar premeditado y sistemático de corrimiento de los indígenas hacia tierras menos fértiles sumado a ciertos desalojos en el área de Alto Río Mayo, hoy existe un gran vacío en la memoria local sobre la presencia indígena de $\mathrm{Cu}$ rruhuinca y su gente [(lo mismo ocurre entre los parientes lejanos que quedaron en la zona del lago Lacar, según los testimonios recogidos (C.Q., Villa La Angostura vía Zoom, junio 2020)]. Si no fuera por escasas menciones topográficas y algunos relatos y testigos, sería muy difícil advertir la presencia de este grupo mapuche en el área. Los indígenas fueron desapareciendo físicamente y de la memoria local; los mecanismos de olvido fueron muy efectivos ya que a poco más de 100 años de su presencia en el lugar, hoy ya casi no se los recuerda y los testimonios materiales son casi efímeros.

Muchos de estos paisanos fueron muriendo en sus sucesivos desalojos, la lucha por conservar sus tierras los expuso a la desesperación, enfermedades y hasta viajes costosos y angustiosos, como los efectuados a la ciudad de Buenos Aires esperando ser recibidos por las autoridades nacionales de turno (Numerosos ejemplos citados en Perea, 1998).

La angustia que genera mucha de la injusticia operada sobre los pobladores indígenas, nos lleva a profundizar lo ocurrido con el grupo de Basilio Curruhuinca. Presentamos a continuación la investigación, aún en proceso, de carácter arqueológico, histórico y antropológico en la zona, la que focaliza en las evidencias en terreno del grupo de este cacique.

\section{Evidencias materiales del asentamiento del cacique Basilio Curruhuinca}

Para 1927 Basilio y su gente, como ya mencionáramos, estaban asentados en viviendas de adobe y zinc, contaban a su vez con galpones y corrales, haciendas y chacras, huertas y sembradíos. Pensamos que evidentemente tenía que haber quedado algún rastro material de este asentamiento, se prospectaron por lo tanto dos sitios cercanos de ocupación indígena de momentos recientes: Tapera Curruhuinca y Puesto Quintoman (Volver a la Figura 1), los únicos sitios identificados por los pobladores locales con el cacique y su grupo; y los que fueron localizados como consecuencia de las entrevistas realizadas en la zona (J.S y J.P.S, Aldea Beleiro 2013, 2016 y 2019 y Alto Río Mayo 2013 respectivamente) y la información histórica consultada (CFI 1927, Expte. 345-2961).

A fin de localizar vestigios de esta ocupación se prospectó un amplio sector conocido localmente como "Tapera Curruhuinca”, ubicado en Alto Río Mayo al borde de un manantial rodeado de arboleda, este sería el lugar en donde se habría asentado 
el cacique Basilio Curruhuinca. En el área no queda ninguna estructura en pie, seguramente por haber sido de adobe (Descripción de la misma en CFI 1927, Expte. 345-2961) y como consecuencia principalmente de la costumbre local de derribar las casas deshabitadas para evitar ocupaciones (testimonio de J.S, Aldea Beleiro, 2016 y 2019). En el terreno y en superficie, a pesar de la ausencia de construcciones visibles, se observó material industrial asignable al siglo XX: 3 fragmentos de porrones de gres; 11 fragmentos de vidrio (algunos de ellos asociados a botellas de cerveza, vino y sidra); 1 lata y 1 trozo de suncho de barril; 1 fragmento de suela de goma con clavos; $y$ material de características indígenas: 5 desechos de talla y 1 guijarro pulido.

La memoria local manifiesta que cuando los colonos llegaron al área fueron "corriendo" paulatinamente de este sector al cacique y su gente hacia el este, algunas veces mediante engaños o compra/ventas desfavorables (Casanueva et al., 2019; Castro Esnal et al., 2016; Castro Esnal y Casanueva, 2018; y testimonios de J.S y J.P.S, Aldea Beleiro 2013, 2016 y 2019 y Alto Río Mayo 2013).

\section{Dos linajes relacionados en el tiempo: Curruhuinca y Quintoman}

La búsqueda de vestigios de la presencia de las personas que conformaron el grupo de Basilio Curruhuinca, condujo a los restos del Puesto Quintoman, cuyos datos también figuran en el Censo Indígena de 1927 (Miranda-Quintoman, Lote 23. CFI 1927, Expte. 345-2961) (Figura 4).

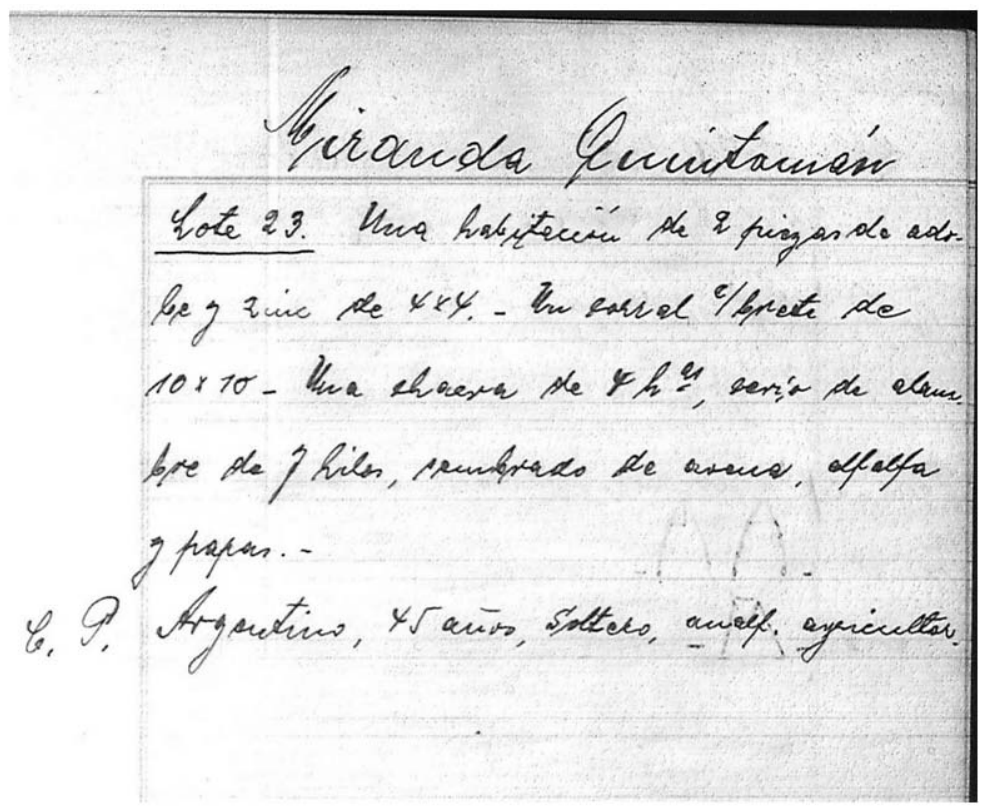

Figura 4: Detalle de los datos registrados correspondientes a "Miranda Quintoman" (“Censo de las Familias Indígenas de 1927” Expte. 345-2961). 
Antes de detallar el trabajo realizado y los resultados obtenidos hasta el momento en este sitio, es importante hacer un poco de historia con respecto a la relación de parentesco entre el linaje Curruhuinca y el Quintoman, para ello hay que remontarse a finales del siglo XIX con el origen de la comunidad Vera ubicada en las cercanías de San Martín de los Andes. Esta comunidad fue fundada por Carlos Vera, nacido en 1877, hijo de Narcisa Curruhuinca hermana del Lonko Bartolomé Curruhuinca. Carlos Vera se casó con Amelia Quintoman dando origen a un nuevo Lof (comunidad en mapudungun) en tierras asignadas por Bartolomé Curruhuinca, las cuales fueron ocupadas en forma efectiva en 1907. Carlos Vera y Amelia Quintoman tuvieron 15 hijos de los cuales cinco fueron el eje de las familias que componen la actual Comunidad Mapuche Vera (Valverde y Stecher, 2006).

El traslado hacia el sur por parte del Estado argentino de una parte de la comunidad de Bartolomé Curruhuinca, hizo que los apellidos Curruhuinca y Quintoman quedaran registrados en documentos, toponimia y memoria local en Alto Río Mayo, entre otros parajes antes mencionados (Perea, 1998).

\section{Puesto Quintoman. Arqueología de la vida cotidiana}

Los restos del Puesto Quintoman (Castro Esnal y Casanueva, 2018) se encuentran sobre una de las barrancas del arroyo Nirihuao que discurre de Oeste a Este, cuyas nacientes provienen de la vecina región de Aysén (Chile), este arroyo encajonado hace varios años atrás se encontraba casi a nivel del terreno, pero sufrió el cambio que se observa en la actualidad después de algunas nevadas muy fuertes (Relato de J.S., Aldea Beleiro, 2019). En el pasado las viviendas y sus huertos, por lo tanto, se ubicaban sobre la línea de costa. Hoy se observa una buena arboleda y algunos calafates crecidos entre los restos de la antigua casa.

En el Puesto Quintoman, durante la última campaña arqueológica de febrero de 2019, se realizó una prospección superficial de la vivienda, sus alrededores y de los dos basurales identificados a ambos lados del arroyo (llevando adelante una recolección superficial selectiva), se levantó la planta de la casa en base a los cimientos existentes en el terreno, se realizó un completo registro fotográfico del área y del material hallado en superficie; asimismo se identificó el antiguo sector de huerta y sembradío en la margen contraria del arroyo (orientados siempre por un vecino y productor local) (Figura 5). 


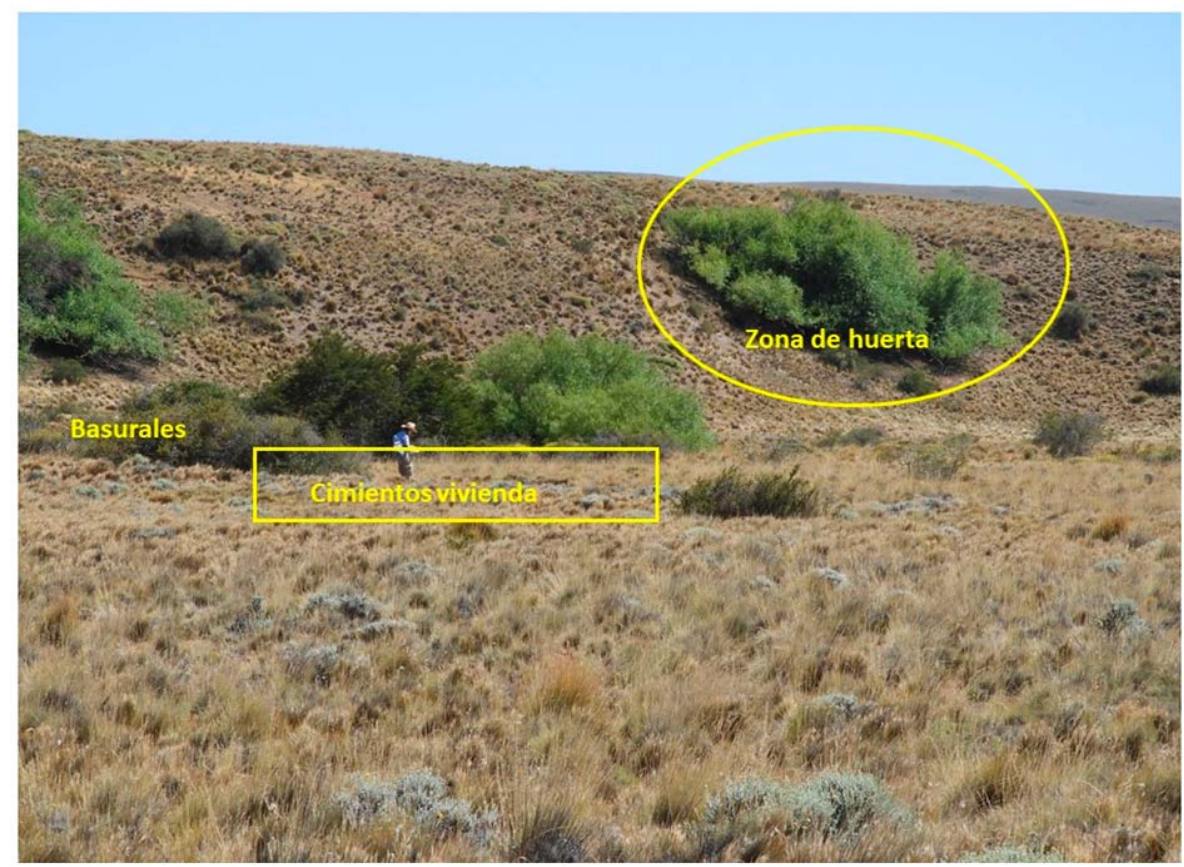

Figura 5. Tareas de prospección en el sector correspondiente al Puesto Quintoman, en la imagen se indica el antiguo sector de huerta, la zona de los basurales y los restos de los cimientos de la vivienda.

De la vivienda original, de dos habitaciones, paredes de adobes y techo de chapa [datos surgidos de vecinos (J.S y J.P.S, Aldea Beleiro, 2016 y 2019) y de la entrevista a N.Q. (Aldea Beleiro 2019), nieto del que pobló y declaró en el Censo de 1927], sólo se observan algunas piedras bola de los desdibujados cimientos (Figura 6) y chapas del techo dispersas muy cerca de los mismos; de los adobes no queda ningún rastro. Casi en ambos extremos de los cimientos han crecido calafates que dificultan ver bien toda la estructura que describe un rectángulo de $16 \mathrm{~m}$ de largo por $5.5 \mathrm{~m}$ de ancho, con una división casi en medio de la vivienda muy desvaída que asoma entre calafates y coirones.

Se proyectan sondeos selectivos durante el próximo trabajo de campo, mientras tanto hasta el momento el relevamiento superficial ha dejado en evidencia algunos objetos testigo de los días transcurridos allí durante las primeras décadas del siglo XX. Entre los restos de las chapas que conformaron la vivienda, se entremezclan variedad de alambres, pedazos de cuero enroscados, pequeñas suelas de zapatos de niños, latas y platos aplastados, una cuchara, un colador, una bisagra metálica, fragmentos de distintos vidrios que conformaron botellas y frascos, también algunos objetos enteros como botellas de vino y cerveza y frascos de farmacia (Algunos de los envases vítreos fueron realizados por soplado y mayoritariamente con técnicas de molde, prensado 
en molde y molde mecanizado o industrializado (Jones, 2000; Pedrotta y Bagaloni, 2004-2006; Rock, 1981); asimismo, sunchos de barril presumiblemente de acero como era costumbre confeccionarlos (Caretti, De Rosa, Landa y Montanari, 2014) los que podrían haber contenido fundamentalmente alguna bebida alcohólica como vino o aguardiente. Muy interesante resulta el frasco de aceite de hígado de bacalao, también conocido como "Emulsión de Scott" (que presenta la figura de un pescador cargando un pescado) (Figura 7). Este jarabe medicinal se recomendaba, entre otros beneficios, para dotar a los niños de una naturaleza fuerte y robusta (Casanueva, 2020).

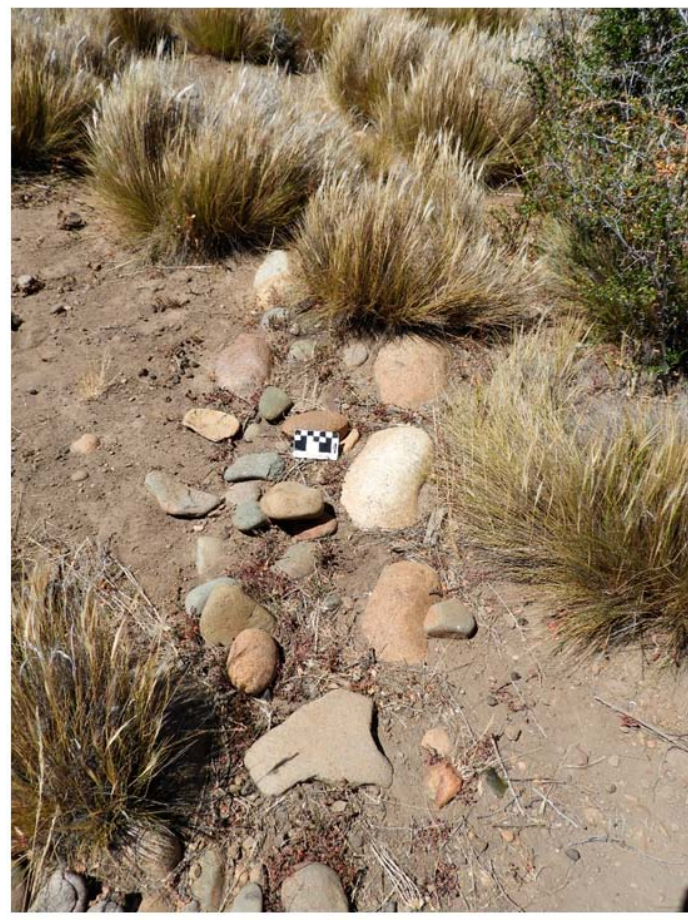

Figura 6: Restos de los cimientos de piedra del Puesto Quintoman. 


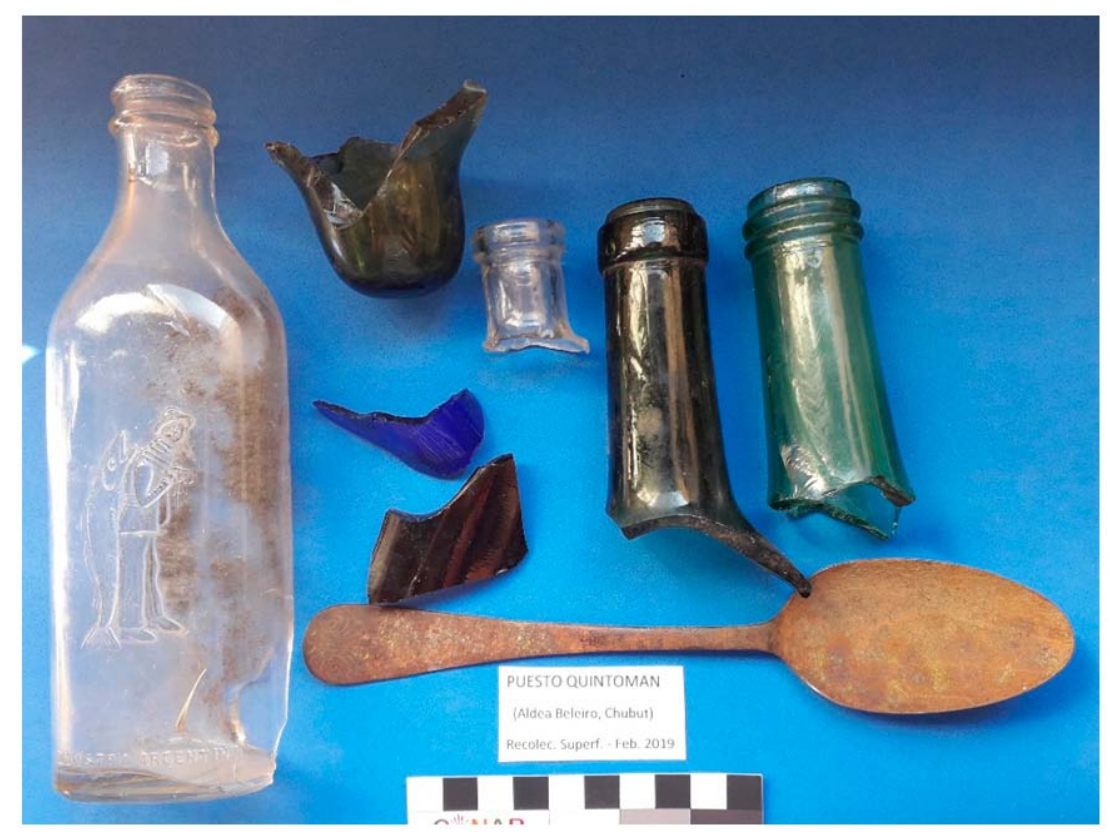

Figura 7: Parte del material arqueológico hallado en Puesto Quintoman, entre los objetos el frasco de "Emulsión de Scott”.

En cuanto a los dos basurales, ubicados a cada lado de la actual barranca casi en el curso del arroyo y conformados alrededor de unos árboles y calafates ya existentes al momento de poblar el lugar (dato aportado por J.S., Aldea Beleiro, 2019), dejan ver superficialmente varias botellas (de cerveza, vino, aperitivos) -estos son antiguos envases de paredes gruesas-, latas, suelas de alpargatas, etc. (Figura 8). El material tiene una cronología relativa que lo ubica en la primera mitad del siglo XX. En las inmediaciones del puesto se halló abundante material lítico (90 desechos de talla, 19 instrumentos, 1 núcleo - análisis efectuado por Analía Castro Esnal) y un fragmento de cerámica indígena (del que se están esperando los resultados del fechado); a su vez, se observaron en las inmediaciones de la vivienda, restos de un posible "chenque"7 saqueado.

7. "Chenque es una palabra araucana que significa: sepultura... El indio araucano o tehuelche o chehuelche, acostumbraba a dar sepultura a sus muertos, en la cima de los altos y escabrosos cerros... Los miembros de la tribu o familia, que moría durante la estancia de la misma en un lugar, era transportado en rusticas parihuelas, a la cresta de un cerro próximo y alli removiendo algunas piedras, se practicaba un pequeño, superficial hoyo, donde se colocaba al muerto, la cabeza al naciente, cubriéndole luego de piedras. El chenque, da sobre la superficie del suelo, la apariencia de un pequeño túmulo" (Testimonio del maestro Domingo Bonzi en la Encuesta Nacional de folklore de 1921, Tercera Serie, Tomo III, No 8 , Tecka, Chubut: 16). 

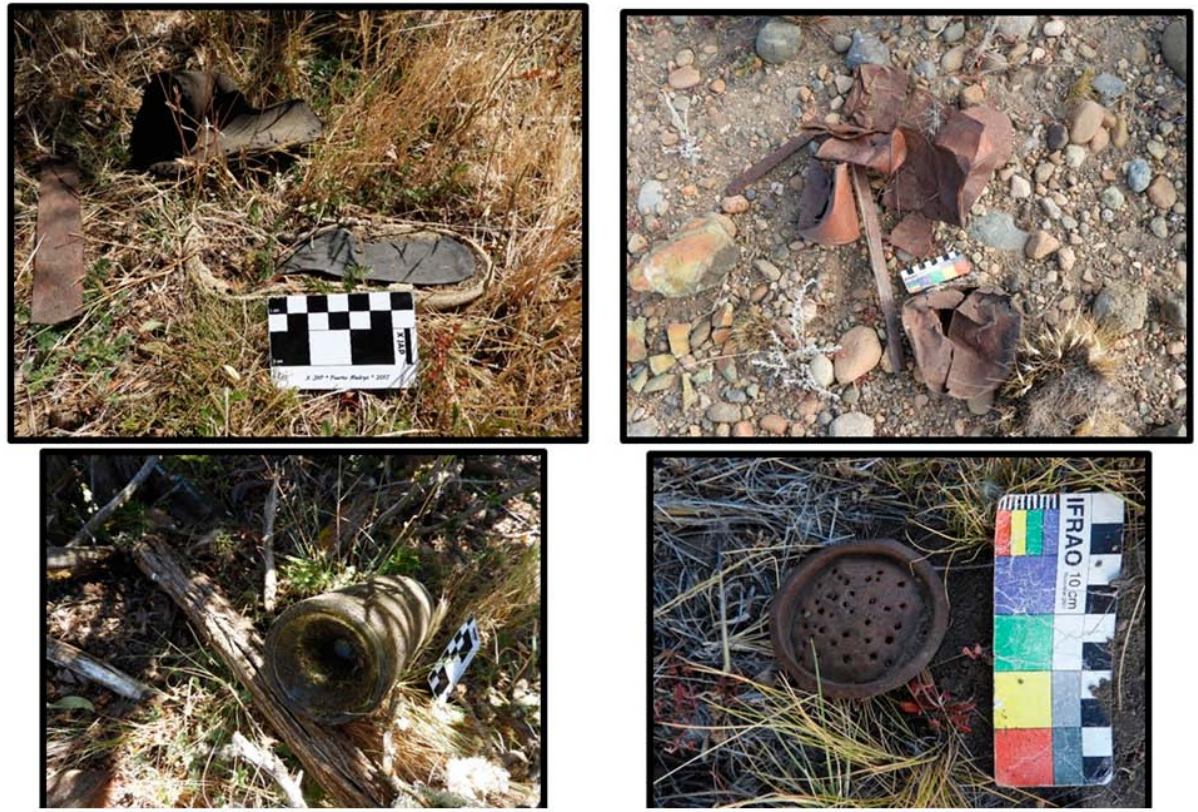

Figura 8: Objetos en superficie hallados en las inmediaciones del Puesto Quintoman y en los basurales.

\section{Recuerdos de infancia}

Cuando N.Q. abandonó su casa como consecuencia de la muerte de su abuelo J. Miranda, contaba con escasos ocho años (1956 aproximadamente). La vivienda fue derrumbada completamente (para evitar que la ocuparan, testimonio de J.S, Aldea Beleiro 2019) y él quedó al cuidado de la familia que compró las tierras (esta familia le facilitó una educación y un oficio, fue considerado miembro de ella y vivió con ellos hasta su reciente fallecimiento en junio 2021). Reflexionando sobre la presencia de N.Q. y su hermano, con el que vivía al momento de la muerte de su abuelo, no es de sorprender las pequeñas suelas de zapatos ni la presencia del aceite de bacalao en una vivienda en la que habitaban niños pequeños.

Mantuvimos una entrevista abierta con N.Q. (Aldea Beleiro, 8 febrero 2019), una charla amena en donde fueron surgiendo de a poco las memorias y los detalles, él mismo nos relató cómo se entretenían de pequeños: "los juguetes los hacíamos con mi hermano, casitas de madera y caballitos, y autos con latas y ruedas de madera". Recuerda "Estábamos mucho tiempo solos, como los chicos de Nyl (vecinos cercanos) que también vivían con su abuelo", a la hora de la siesta "a veces siestábamos y sino jugábamos o hacíamos macanas...con los chicos de Nyl....

Aquellos niños se alimentaron con la abundante huerta de su abuelo "mi abuelo tenía chacra con papas, zanahorias, lechuga, nabos, acelga, rabanitos, arvejas... Las 
ovejas se comían las hojas y por eso con mi hermano teníamos que ir con los perros para que las ovejas no se comieran la lechuga de la chacra". También recuerda que "cocinábamos en una olla grande de hierro enlozada. Comíamos guiso con verduras". A su vez nos habló de las "choiqueras" (bolas de boleadoras más pequeñas utilizadas para cazar choiques), que las hacían ellos y su abuelo "con soga, pedazos de cuero con un tiento que tironeábamos bien", recordaba que comían huevos de choique cuando eran chicos. Vemos la complementación de la dieta con una práctica de cazadores indígenas (Casanueva, 2020).

Preguntando sobre las suelas de zapatos halladas en las inmediaciones de la casa, N.Q. contó que "había un zapatero y cuando se rompía la suela la sacaban y la cambiaban por otra nueva". En cuanto a los recuerdos de la casa donde vivía con su abuelo y hermano, N. Q. cuenta que "la casa era con una habitación grande, con 4/6 camas". En otra charla con un vecino éste recuerda que cuando él era pequeño, 4 o 5 años "iba a visitar al abuelo y a N. Q. y su hermano... la casa era de dos habitaciones, cada una con una puerta dividida en dos, la parte de abajo se quedaba fija y la de arriba hacía de ventana, las dos daban hacia el este... la casa era de adobes y techo de chapas..." (Relato de J.S., Aldea Beleiro, 9 febrero 2019).

\section{Algunas interpretaciones}

Consideramos que las memorias recuperadas de personas concretas, le dan alma tanto al documento de 1927 como a los cimientos y objetos diseminados en el terreno, los recuerdos de infancia refuerzan el escrito, brindan detalles de la vida cotidiana, lúdica, doméstica y productiva, avalan el tipo de economía anunciado en el documento y las características de las casas y sus alrededores. Mientras que la cultura material, además de permitir un acercamiento a las características constructivas de la vivienda (manifiestas en los cimientos, las chapas del techo, bisagras, cerradura, clavos, arandelas y alambres), brinda información sobre distintas prácticas, como las culinarias (envases de bebidas, recipientes de lata, platos, cuchara, colador hecho con una lata), de cuidado personal (distintos tipos de frascos, entre ellos uno medicinal), de vestimenta (suelas de zapatos y una alpargata casi desintegrada), el comercio en la zona atestiguado por la manipulación de objetos culinarios, contenedores de alimentos y bebidas como las latas, los frascos, botellas y barriles (estos últimos intuidos a través de los sunchos) (Casanueva, 2020).

Estos objetos y fragmentos, tanto por sus características morfo-funcionales como por las tecnologías utilizadas para su confección, como ya se adelantara, se asocian al siglo XX y se entremezclan con objetos realizados con técnicas indígenas como desechos de talla, instrumentos hechos en piedra para procesamiento y caza, un fragmento de cerámica y en las cercanías de la antigua vivienda y en la ladera de una loma, restos de una estructura que posiblemente corresponda a un "chenque" (Casa- 
nueva et al., 2019). El material indígena y el chenque serían de momentos anteriores a la ocupación del cacique Curruhuinca y su grupo ${ }^{8}$; inclusive para los momentos de asentamiento de este grupo ya las familias no utilizarían la técnica de chenque como enterratorio sino sus inhumaciones serían del tipo "cristiano" (Domingo Bonzi, Encuesta Nacional de folklore de 1921, Tercera Serie, Tomo III, N8, Tecka, Chubut: 17) en las cercanías de las viviendas e inclusive con cruces, similar a la forma de entierro de la familia de N.Q.

\section{Consideraciones finales}

Se sabe que, luego de las campañas militares de avance contra el indígena a finales del siglo XIX, y en conformidad con la idea de Nación que se impuso desde el Estado argentino, las nuevas configuraciones del espacio, ocurridas luego de los traslados, movimientos, desmembramientos y reagrupaciones que caracterizaron a las primeras décadas posteriores a las conquistas militares, refirieron a nuevos discursos que recrearon el territorio de la nación como uniforme, sin tiempo ni etnicidad (Delrío, 2005, p. 88), alimentando la invisibilización de los indígenas y rotulándolos como "argentinos" en la documentación de los registros estatales, en post de la supuesta uniformidad nacional. Esta invisibilización y homogeneización fue la que imperó en nuestra área de la mano de los documentos elaborados luego de las inspecciones estatales de las zonas ocupadas por las familias indígenas.

Esta investigación busca aportar a la memoria local e intenta recuperar el sentir y la cotidianeidad de los hoy casi desconocidos y olvidados habitantes mapuches de Alto Río Mayo. Se pretende a su vez, reconocer el doble desarraigo al que fueron sometidos, ya que antes de ser ubicados en este último asentamiento de donde fueron desalojados paulatinamente durante el siglo XX, primero fueron extraídos de sus tierras ancestrales en las márgenes del lago Lacar. Se sabe que para esta comunidad el territorio, elegido por sus antepasados, posee un marcado valor histórico-simbólico, cada Lof de la comunidad mapuche posee modos de vida propios (Valeri, 2020; Valverde y Stecher, 2006), lo mismo ocurre con las identidades familiares y territoriales; cada Lof recrea la relación con su propio entorno geográfico y socio-territorial y a través de las ceremonias y rogativas se fortalece el sentido de identidad territorialmente amplio (Valeri, 2020). El desplazamiento forzado y los desmembramientos familiares,

8. El maestro Domingo Bonzi en su testimonio relató que "En la casi totalidad de manantiales, encontramos vestigios,... de una familia o tribu de indios. Flechas de cuarzo o sílice, puntas de lanzas del mismo material, huesos, piedras, etc., son frecuentemente encontrados a orillas de los manantiales" (Testimonio de Domingo Bonzi en la Encuesta Nacional de Folklore de 1921, Tercera Serie, Tomo III, Nº, Tecka, Chubut: 16). El Puesto Miranda-Quintoman se encuentra sobre un arroyo, seguramente lugar de aprovisionamiento de recursos y pernocte de grupos indígenas en el pasado. 
representaron una notoria e irreparable pérdida de su historia ancestral e identitaria, culminando con un desesperado deambular en post de tierras propias y el, constantemente negado, reconocimiento de sus derechos como ciudadanos argentinos.

Las distintas acciones y situaciones de los individuos o familias que se asentaron en el área bajo estudio -excediendo sus historias particulares-, remiten a sucesos propios de una historia social local acorde con la historia de una región y de un país. El abordaje y la metodología aquí propuestos, permiten un acercamiento a las pequeñas historias locales las que posibilitan identificar grandes procesos socio-históricos como: desigualdad territorial, límites impuestos por dos estados nacionales vecinos que se encontraban definiendo y fortaleciendo sus fronteras, indígenas trasladados forzosamente luego de los avances militares de finales del siglo XIX, inmigración y asentamientos colonos en las nuevas áreas productivas, luchas por la tenencia y ocupación definitiva de las tierras, un Estado mezquino con los indígenas con fuerte apoyo a colonos, inmigrantes, compañías y comerciantes que representaban el ideal económico productivo que buscaba imponerse en la Patagonia ganadera del siglo XX, etc.

En definitiva, son los restos materiales los que aún perduran y permiten reconstruir la cotidianeidad de los niños y adultos que vivieron, construyeron y soñaron el pequeño espacio de tierra que les fue cedido; la materialidad afirma su existencia y les vuelve a dar voz (Casanueva et al., 2019). A su vez, desde la arqueología histórica se plantea como desafío el abordaje de momentos históricos recientes en los que existen marcadas similitudes entre asentamientos de europeo-criollos e indígenas con economías agropastoriles; donde las formas de ocupar el espacio, la producción y manipulación de objetos de la vida doméstica cotidiana no revisten distinciones notorias, y son evidencia del avance del capitalismo en la región (Agnolin y Nuevo, 2016; Casanueva et al., 2019; Castro Esnal y Casanueva, 2018). Por lo tanto, un registro arqueológico asociado comúnmente a colonos inmigrantes o criollos, puede corresponder también a un asentamiento indígena. El tipo de evidencia arqueológica, como la hallada en la zona de Tapera Curruhuinca y Puesto Quintoman, no es excluyente de ninguno de los grupos sociales que se asentaron en esta zona.

La articulación de líneas de evidencia independientes, en conclusión, permite hacer visibles determinados actores tradicionalmente silenciados en los discursos hegemónicos. En síntesis, esta investigación, además de permitir reconstruir las historias recientes indígenas, los traslados forzosos después de las campañas militares y décadas después por autoridades, comerciantes y algunos colonos inescrupulosos, orienta también en el manejo de tierras en la frontera y la ocupación definitiva del otrora espacio concedido a las familias indígenas; los actuales restos materiales de su efímero asentamiento alertan acerca de su presencia y lo difícil que sería identificarla si no fuera por lo que aún se conserva en la memoria, en los relatos de los pocos testigos y en ciertos documentos y nombres de parajes. 


\section{Agradecimientos}

A Analía Castro Esnal, con quien trabajamos codo a codo indagando sobre la vida indígena reciente en la zona, asimismo por la lectura de este trabajo y la confección del mapa presentado. A todo el resto del equipo de investigación: Cecilia Pérez de Micou, Silvia García, Mariana Sacchi, Lucía Gutiérrez, Florencia Ronco y Mailín Campos. A Nora Kuperszmit por facilitarnos y poner a nuestra disposición el documento histórico de 1927; a Alberto Pérez por los muchos intercambios sobre la Comunidad Curruhuinca; a la Familia Solsona por su incondicional apoyo y hospitalidad; a la Comuna de Aldea Beleiro y a la comunidad de Río Mayo; a C. Quintoman y A. Curruhuinca. Dedicado a la memoria de nuestro querido amigo Narciso Q. A las/os evaluadoras/os que enriquecieron el trabajo con sus sugerencias y comentarios.

\section{Referencias}

Acuto, F., y Zarankin, A. (1999). Introducción: Aún sedientos. En A. Zarankin y F. Acuto (eds.), Sed non Satiata. Teoría Social en la Arqueología Latinoamericana contemporánea (pp. 7-15). Buenos Aires: Ediciones del Tridente. Colección científica.

Agnolin, A., y Nuevo, A. (2016). "Arrinconamiento y marginalidad durante el siglo XX: La evidencia arqueofaunística de los sitios Puesto Yatel y puesto Quintillán (Centro oeste de la provincia de Santa Cruz, Patagonia argentina)". F. Mena (Ed. Principal). Arqueología de la Patagonia: de mar a mar (pp. 381-389). Santiago, Chile. Ediciones CIEP / Ñire Negro Ediciones.

Aguado, A. (2007). La colonización del oeste de la Patagonia central. Departamento Río Senguer, Chubut. 1890/1919. Buenos Aires. Imprenta Bibliográfika.

Baeza, B. (2007). Los inspectores de tierra como productores identitarios de la frontera chileno-argentina en Patagonia Central. Séptimo Congreso de Historia Social y Política de la Patagonia Argentino-Chilena, Historia, investigación e investigadores en y de la Patagonia. Octubre 2007. Trevelin, Chubut, Argentina. Recuperado de https://iesyppat.files.wordpress.com/2009/06/baezainspectores.doc.

Barrionuevo, F., y Beleiro, M. (2015). Un pionero y su familia en Aldea Beleiro: la trayectoria de Don Rafael Beleiro. Comodoro Rivadavia.

Bellelli, C. (1999). Arqueología. Como el presente devela el pasado. En M. Garreta y C. Bellelli (comps.). La trama cultural. Textos de antropología y arqueología (pp. 65-76). Buenos Aires. Ediciones Caligraf.

Brittez, F. (1998/2004). Arqueología rural en el partido de General Brandsen, provincia de Buenos Aires. En C. Gradín y F. Oliva (eds.). La Región Pampeana, su pasado arqueológico. Actas del I ${ }^{\circ}$ Congreso de Arqueología de la Región Pampeana Argentina (pp. 211-222). Venado Tuerto, Laborde Editor. 
Buscaglia, S., y Bianchi Villelli, M. (2009). Introducción al simposio Patagonia y sus fuentes. Un estado de la cuestión. M. Salemme, F. Santiago, M. Álvarez, E. Piana, M. Vázquez y M. E. Mansur (comps.). Arqueología de la Patagonia. Una mirada desde el último confín. Tomo 1 (pp.137-147). Ushuaia, Tierra del Fuego. Argentina. Editorial Utopías.

Caretti, F., De Rosa, H., Landa, C., y Montanari, E. (2014). ¿Tinto o blanco?: Caracterización de sunchos de barril del sitio Posta El Caldén (La Pampa, fines del siglo $X I X)$. Congreso Internacional de Metalurgia y Materiales. sam-conamet/iberomat/materia. Santa Fe, Argentina.

Casanueva, M. (2020). Objetos, memorias y documentos: la historia indígena reciente de Aldea Beleiro, un pequeño poblado al SO de Chubut. Novedades de Antropología. INAPL., 29 (88), 3-8.

Casanueva, M. (2016). Una visión arqueológica de la arquitectura doméstica en la Patagonia argentina de los siglos XVIII, XIX y XX. En F. Mena (ed.), Arqueología de Patagonia: de mar a mar (pp. 69-79). Santiago de Chile: Ediciones CIEP y Nire Negro Ediciones.

Casanueva, M. (2013). Colonos e Indígenas por Tierras Patagónicas. Una mirada arqueológica de la vida cotidiana transcurrida durante los siglos XVIII, XIX y XX. Saarbucken, Alemania. Publicia Editorial.

Casanueva, M. (2010). Paredes que hablan: Historia de una tapera. Arqueología de los primeros colonos europeos en el Valle de Piedra Parada (Chubut, Argentina). En A. Malbrán Porto y E. Méndez Torres (coors.). Memorias del I Congreso de Folklore y Tradición Oral en Arqueología (pp. 125-140). Coyoacán, Ciudad de México, México. Escuela Nacional de Antropología e Historia.

Casanueva, M. (2005). Arqueología de tiempos históricos. La estancia bonaerense como territorio fronterizo. Aproximaciones contemporáneas a la arqueología pampeana. Perspectivas teóricas, metodológicas, analíticas y casos de estudio (pp.113127). Bolívar, Buenos Aires. Facultad de Ciencias Sociales, Universidad Nacional del Centro de la Provincia de Buenos Aires.

Casanueva, M., Castro Esnal, A., y Pérez de Micou, C. (2019). Indígenas, colonos y colonos indígenas. Arqueología de tiempos históricos y su abordaje. Una experiencia en el SO de Chubut, Patagonia argentina. En J. Gómez Otero, A. Svoboda y A. Banegas (eds.). Arqueología de la Patagonia: el pasado en las arenas (pp. 93-104). Puerto Madryn, Chubut. Instituto de Diversidad y Evolución Austral.

Castro, A. (2014). Camino y Piedra. Rutas indígenas y Arqueología en la provincia de Chubut. Buenos Aires: Fundación de Historia Natural Félix de Azara. 
Castro Esnal, A., Gutiérrez, L., Ronco, F., y Pérez de Micou, C. (2020). Uso del espacio y organización tecnológica en la Colonia El Chalía, sudoeste de Chubut, Argentina. Revista del Museo de Antropología, 13 (2), 27-38.

Castro Esnal, A. y Casanueva, M. (2018). Arqueología e historia en Aldea Beleiro (SO Chubut). Antiguos y nuevos habitantes de la cueva Casa de Piedra de Roselló y sus alrededores. Revista Arqueología, 24 (2), 247-257.

Castro Esnal, A., Pérez de Micou, C., y Casanueva, M. (2017). Early Holocene Occupation of the Forest-Steppe Ecotone of Southern South America: Evidence from Casa de Piedra Roselló Cave (Chubut, Patagonia Argentina). Paleoamerica, 1-7 Recuperado de http://dx.doi.org/10.1080/20555563.2017.1330102.

Castro Esnal, A., Casanueva, M., Sacchi, M., y Pérez de Micou, C. (2016). Estudios arqueológicos en Aldea Beleiro, SO del Chubut, Argentina. Nuevos fechados para el sitio Casa de Piedra. Revista del Museo de Antropología de Córdoba, 9 (1), 7-12.

Castro Esnal, A., Sacchi, M. y Pérez de Micou, C. (2011). Aspectos generales de la tecnología lítica de los sitios de Colonia El Chalía (SO de la provincia de Chubut, Argentina). International Journal of South American Archaeology, 9, 28-40.

Censo de las familias Indígenas de 1927 (Inspección compuesta por las tribus de los Caciques Manuel Quilchamal y Basilio Curruhuinca y sus haciendas). Gobernación del Chubut. Expediente 345-2961. Instituto Autárquico de Colonización y Fomento Rural de Chubut (IAC). Rawson.

Cirigliano, N. (2016). Movilidad de grupos indígenas y aprovechamiento de materias primas entre el extremo sur del macizo del Deseado y la cuenca del río Santa Cruz durante los últimos 2000 años (Provincia de Santa Cruz, Argentina). (Tesis de Doctorado MS). Universidad de Buenos Aires, Facultad de Filosofía y Letras.

Dal Molin, C. (1998). Hoja Geológica 4572-IV Alto río Senguer. Programa Nacional de Cartas Geológicas de la República Argentina SEGEMAR, № 255.

Delrío, W. (2010). Del no-evento al genocidio. Eadem Utraque Europa. Revista de Historia Cultural e Intelectual, 6 (10/11), 219-254.

Delrío, W. (2005). Largos peregrinajes (1885-1904). Memorias de expropiación. Sometimiento e incorporación indígena en la Patagonia (1872-1943). Cap. 3 (p. 143). Bernal, Universidad Nacional de Quilmes.

Encuesta Nacional de Folklore de 1921. Facultad de Filosofía y Letras. Instituto de Literatura Argentina. Colección de Folklore. Tercera Serie, Tomo III, Nº, Chubut, 1, Domingo B. Bonzi (Quichaura, Tecka, Escuela "Los Pocitos") Mallín Grande. Fojas 20. Costumbres tradicionales: el chenque (pp.16-18). Encuestas realizadas en enero 1922. 
Dumrauf, C. (1981). Las Últimas Campañas Militares del Sur (1883-1884). Por Fundación de Apoyo al Instituto Universitario Trelew - 198G-81. Talleres Gráficos de la Secretaría General de la Gobernaci6n del Chubut, Argentina.

García, S. (2009). Educación institucional y educación familiar. El caso de la Reserva del Chalía en la provincia del Chubut. En C. Pérez de Micou, M. Trivi de Mandri y L. S. Burry (Eds.) Imágenes desde un alero. Investigaciones multidisciplinarias en Río Mayo, Chubut Patagonia Argentina (pp. 163-174). Buenos Aires. Fundación Azara.

García, S., Pérez de Micou, C., Casanueva, M., Castro, A., Funes, M., y Sacchi, M. (2009). El uso de testimonios orales en la arqueología del Chubut. IX Encuentro Nacional y III Congreso Internacional de Historia Oral: "los usos de la memoria y la historia oral”. 7, 8 y 9 de octubre de 2009 (p. 22). Ciudad Autónoma de Buenos Aires. Dirección General Patrimonio e Instituto Histórico, Subsecretaria de Cultura del Ministerio de Cultura de la Ciudad de Buenos Aires.

Ginzburg, C. (1994). Microhistoria: dos o tres cosas que se de ella. Revista d'Història Moderna. Manuscrits, 12, 13-42.

Goñi, R. (2013). Reacomodamientos poblacionales de momentos históricos en el noroeste de Santa Cruz. Proyecciones arqueológicas. En A. F. Zangrando, R. Barberena, A. Gil, G. Neme, M. Giardina, L. Luna, C. Otaola, S. Paulides, L. Salgán y A. Tívoli (comps.) Tendencias teórico-metodológicas y casos de estudio en la Arqueología de Patagonia (pp. 69-76). San Rafael, Mendoza. Museo de Historia Natural de San Rafael, Sociedad Argentina de Antropología e Instituto Nacional de Antropología y Pensamiento Latinoamericano.

Habegger, V. (2007). El mundo indígena frente a la dominación estatal. Norpatagonia, fines del siglo XIX - principios del siglo XX. Mundo Agrario, 8, 15.

Jones, O. (2000). Glass bottle push-ups and pontil marks. Approaches to material culture research for historical archaeologists. En D. R. Brauner (comp.). California, Pennsylvania, EEUU (pp. 149-160). Published by Society for Historical Archaeology. Ronald L. Michael Editor.

Levi, G. (1993). Sobre microhistoria. En P. Burke (ed.) Formas de hacer Historia (pp. 119-143). Madrid, Alianza Editorial.

Lumbreras, L. (2005). Arqueología y Sociedad. En E. González Carré y C. Del Águila (eds.), Lima, Instituto de Estudios Peruanos, Museo Nacional de Arqueología y Antropología (pp.21-43). INDEA. Serie Historia Andina.

Maggiori, E. (2007). Aldea Beleiro. Historia de un pequeño pueblo de frontera. Rawson, Chubut. Secretaría de Cultura de la Provincia de Chubut. 
Montañés Serrano, M. (2001). Dinámica, funcionamiento y contenido de las entrevistas individuales y grupales. En T. Rodríguez Villasante; M. Montañés y J. Mati (coords.). Prácticas locales de creatividad social/2 (pp. 83-95). Barcelona, El Viejo Topo.

Muñiz, M., y Perea, E. (2000). La Reserva del Chalía. La tierra del cacique tehuelche Manuel Kéltchamn y su tribu. Río Mayo, Chubut, Argentina.

Musso, L. (2015). Crónicas de dos familias pioneras y su entorno. Familias Beleiro y Musso. Río Mayo, Chubut. Vela al Viento Ediciones patagónicas. Segunda Edición.

Nacuzzi, L., y Lucaioli, C. (2011). El trabajo de campo en el archivo: campo de reflexión para las Ciencias Sociales. Publicar en Antropología y Ciencias Sociales, año IX (10), 47-62.

Novick, S. (2002). Legislación referida a censos y estadísticas en la argentina: 18541991. Ponencia presentada al XIII World Congress of the International Economic History Association (IEHA), Session N 80: "Estatistical and cartographic information in State and market building processes, 18 th- 20th century", Buenos Aires. Recuperado de http://biblioteca.clacso.edu.ar/Argentina/iigg-uba/20161125024358/ PONNovicklegislacion.pdf.

Nuevo Delaunay, A., Goñi, R., Jiménez, N.L., y Cecuk, L. (2014). Marginalidad y adecuación en el siglo XX: dos casos de estudio en la cuenca del lago Strobel. En R. Goñi, J. B. Belardi, G. Cassiodoro y A. Re (eds.), Arqueología de las cuencas de los lagos Cardiel y Strobel. Poblamiento humano y paleoambientes en Patagonia (pp. 187-198). Buenos Aires, Aspha.

Pedrotta, V., y Bagaloni, V. (2004-2006). Circulación, uso y descarte de recipientes de vidrio en la frontera sur. El caso de los indios amigos. En IX Encuentro de historia y arqueología histórica. Historia y arqueología histórica de los pueblos al sur del Salado (pp. 119-135). Olavarría, Buenos Aires. Comisión Municipal de Estudios Históricos y Arqueología Histórica. Municipalidad de Olavarría.

Perea, E. (1998). Sucedidos entreverados en viejos documentos de la Patagonia 19201940. Alto Río Senguer - Chubut. Comodoro Rivadavia, Chubut, Argentina. Editorial Universitaria de la Patagonia. Universidad Nacional de la Patagonia San Juan Bosco.

Pérez, A. (2015). Lofche Curruhuinca. Aportes documentales para el conocimiento de su territorio y linaje. Secretaría Parlamentaria. Buenos Aires. Dirección General de Publicaciones del Honorable Senado de la Nación Argentina.

Pérez de Micou, C., Sacchi, M., Castro Esnal, A., y Funes, M. (2009). Estudios de Arqueología en la Colonia Indígena de Chalía, Dpto. Senguer, Chubut. En P. F. Azar, E. M. Cúneo y S. N. Rodríguez (eds.). Tras la senda de los ancestros: Arqueología de Patagonia. Edición electrónica en CD, sin paginación. San Carlos de Bariloche. Universidad Nacional del Comahue. 
Pinotti, L. (2004). Aquellos Tehuelches. Buenos Aires, Proyecto Editorial.

Pinotti, L. (2001). Sin embargo existimos. Reproducción biológica y cultural de una comunidad tehuelche. Eudeba.

Quiroga, L. (2005). Disonancias en arqueología histórica: la experiencia del valle del Bolsón. Revista Werken, 7, 89-109.

Ramos, M. (2002). El proceso de investigación en la denominada arqueología histórica. Arqueología Histórica Argentina. Actas del $1^{\circ}$ Congreso Nacional de Arqueología Histórica (pp. 645-658). Buenos Aires. Ediciones Corregidor.

Revel, J. (1995). Micro-análisis y construcción de lo social. Anuario del Instituto de Estudios Históricos y Sociales, 10, 125-143.

Rock, J. (1981). Glass Bottles: Basic Identification. Region 5, USDA. Klamath National Forest.

Sacchi, M. (2012). Materias Primas Liticas y Redes Sociales entre los grupos cazadores-recolectores de Patagonia Centro-Meridional. (Tesis Doctoral). Facultad de Filosofía y Letras. Universidad de Buenos Aires. Argentina.

Valeri, P. (2020). Gejupun y WiñoyXipantv en comunidades mapuche de la provincia del Neuquén. Novedades de Antropología. INAPL., 30 (89), 3-7.

Valverde, S., y Stecher, G. (2006). Los Proyectos de desarrollo, trasformaciones productivas, organizacionales y reivindicaciones territoriales: el caso de la comunidad Mapuche Vera (San Martín de los Andes, Provincia de Neuquén). Revista THEOMAI / THEOMAI Journal. Estudios sobre Sociedad, Naturaleza y Desarrollo / Society, Nature and Development Studies, 13.

Whiteley, P. (2002). Archaeology and oral tradition: the scientific importance of dialogue. American Antiquity, 67(3), 405-415.

\section{Sobre la autora}

María Laura Casanueva es Doctora en Arqueología, y Licenciada y Profesora en Ciencias Antropológicas por la Facultad de Filosofía y Letras de la Universidad de Buenos Aires. Es Investigadora del Instituto Nacional de Antropología y Pensamiento Latinoamericano (INAPL). Especializada en Arqueología Histórica, se focaliza en el estudio de distintas situaciones de contacto entre poblaciones europeo-criollas e indígenas de la Patagonia argentina, centrándose en los diversos procesos de construcción social en ámbitos fronterizos de contacto interétnico durante los siglos XVIII, XIX y XX. Correo Electrónico: mlauracasanueva@gmail.com. D https:/ / orcid.org/0000-0001-9146-2750 


\title{
CUHSO
}

Fundada en 1984, la revista CUHSO es una de las publicaciones periódicas más antiguas en ciencias sociales y humanidades del sur de Chile. Con una periodicidad semestral, recibe todo el año trabajos inéditos de las distintas disciplinas de las ciencias sociales y las humanidades especializadas en el estudio y comprensión de la diversidad sociocultural, especialmente de las sociedades latinoamericanas y sus tensiones producto de la herencia colonial, la modernidad y la globalización. En este sentido, la revista valora tanto el rigor como la pluralidad teórica, epistemológica y metodológica de los trabajos.

\author{
EDITOR \\ Matthias Gloël \\ CoORdinadora EDITORIAL \\ Claudia Campos Letelier \\ Corrector de ESTILO Y DiSEÑAdor \\ Ediciones Silsag \\ Traductor, CORRECTOR LENGUA INGLESA \\ Aurora Sambolin Santiago \\ SITIO WEB \\ cuhso.uct.cl \\ E-MAIL \\ cuhso@uct.cl
}

LICENCIA DE ESTE ARTÍCULO

Creative Commons Atribución Compartir Igual 4.0 Internacional 